\title{
A biological monitoring assessment of exposure to methylene dianiline in manufacturers and users
}

\author{
J Cocker, B P Nutley, H K Wilson
}

\begin{abstract}
This paper describes a cross sectional study in which biological monitoring was used to assess exposure to methylene dianiline (MDA) in a selection of United Kingdom industries that manufacture or use MDA. Samples of urine were collected from 411 workers, representing 45 factories engaged in various activities. All urine samples were analysed for MDA and its acetyl metabolites and results are reported as total MDA. In this study, $91 \%$ of postshift urine samples and $88 \%$ of preshift samples had less than $50 \mathrm{nmol}$ MDA/mmol creatinine. Some evidence was obtained which showed that when exposure to MDA was through inhalation (as solid material or contaminated dust), postshift urine samples had higher MDA concentrations than samples taken preshift the next day. When exposure was most likely to be through the dermal route, urine samples taken preshift next day tended to have higher MDA concentrations than urine samples collected immediately postshift on the day of exposure. Therefore a biological monitoring sampling strategy for MDA must take account of the route of entry into the body. If exposure is likely to be via inhalation, postshift samples should be collected and if exposure is likely via the skin, preshift samples next day are more appropriate. The results show that in most factories, regardless of the route of exposure, it is possible to keep urinary MDA concentrations below $50 \mathrm{nmol} / \mathrm{mmol}$ creatinine. In the absence of a health based or hygiene based standard, the use of a "yardstick" as a target to aim for, which has been derived from good working practice across the industry, may be a useful way of helping to control exposure.
\end{abstract}

(Occup Environ Med 1994;51:519-522)

Occupational Medicine and Hygiene Laboratory, Health and Safety Executive, Broad Lane, Sheffield S3 7HQ, UK

J Cocker

B P Nutley

$\mathrm{H}$ K Wilson

Correspondence to:

Dr J Cocker

Accepted for publication 8 April 1994
Methylene dianiline (MDA, also known as 4,4'-diaminodiphenylmethane) is manufactured and used in the United Kingdom as a curing agent in some epoxy resins and polymers. It is genotoxic in vitro inducing point mutations in bacteria in the presence of induced rat liver S9, and unscheduled DNA synthesis in isolated hepatocytes. ${ }^{12}$ In a two year study in rats and mice, MDA was found to be carcinogenic, producing liver and thyroid tumours. ${ }^{3}$ The mechanism for this car- cinogenicity is not clear. There is, however, evidence which suggests that these tumours may have arisen via a non-genotoxic mechanism. Epidemiological evidence for human cancers associated with exposure to MDA is weak. The International Agency for Research on Cancer currently places MDA on its group 2B list: "this agent is possibly carcinogenic to humans."

It is evident from the vapour pressure of MDA that inhalation of MDA vapour is unlikely to be a major route of exposure, unless the MDA is heated. The inhalation of dust, when MDA is handled as a flake, however, may be an important route of exposure, along with the possibility of skin absorption. Because of the ease with which MDA is absorbed through the skin, ${ }^{4}$ air monitoring may not always give an adequate picture of overall exposure. Biological monitoring for $\mathrm{MDA}$ and its metabolites in urine can give a useful estimate of the internal dose of MDA absorbed via all routes of exposure ${ }^{5}$; although the results cannot be related to health effects or used to show compliance with an occupational exposure standard. Biological monitoring certainly has a useful part to play in detecting deterioration in standards of control.

It is important to be able to put data provided by biological monitoring in context. For some toxic substances it may be possible to set a health based standard or a value equivalent to a hygiene limit that corresponds to a biological end point. Present knowledge does not permit such standards to be set for MDA. This situation does not preclude, however, the desirability and usefulness of setting a "target" value. To do this, baseline data must be established based on existing practices. In this study we collected biological monitoring data for workers exposed to MDA in various industries in the United Kingdom.

\section{Methods}

STUDY DESIGN

Forty five companies participated in the study, which was carried out during 1989-90. They were selected on a random one in five basis from manufacturers' sales lists to give a representative cross section of activities in which MDA was manufactured or used in the United Kingdom. The activities fell into nine categories-namely, manufacturing and formulation, paint making, formulation and packing, pattern and tool making, composite materials, potting and encapsulation, casting 
Distribution of urinary MDA concentrations in postshift and preshift samples

\begin{tabular}{lll}
\hline $\begin{array}{l}\text { Urine MDA concentration } \\
\text { (nmol/mmol creatinine) }\end{array}$ & $\begin{array}{l}\text { Postshift samples } \\
(\%)\end{array}$ & $\begin{array}{l}\text { Preshift samples } \\
(\%)\end{array}$ \\
\hline None detected & 57 & 42 \\
$<30$ & 88 & 82 \\
$<50$ & 91 & 88 \\
$<100$ & 96 & 94 \\
\hline
\end{tabular}

and moulding, miscellaneous, and unknown. Information was collected on the nature of the work and the approximate use of MDA. Four hundred and eleven workers (all men) who were potentially exposed to MDA gave their informed consent and volunteered to give urine samples $(25 \mathrm{ml})$, which were collected at the end of the working shift (postshift) and again on the next day (preshift) before work began. Samples arrived in the laboratory within 24 hours where they were stored at $-20^{\circ} \mathrm{C}$ until ready for analysis. Urine samples collected on a Friday were stored at $-20^{\circ} \mathrm{C}$ and dispatched on the next Monday.

\section{ANALYTICAL METHOD}

The method used to analyse the acetyl and diacetyl metabolites of MDA has been reported elsewhere. ${ }^{5}$ Briefly, the metabolites were hydrolysed in $5 \mathrm{M}$ sodium hydroxide to MDA, extracted and then derivatised with pentafluoropropionic anhydride. The MDA derivative was separated on a capillary gas chromatographic column and measured by gas chromatography-mass spectrometry. An internal quality control scheme for MDA was in operation and the day to day coefficient of variation was less than $10 \%$. Creatinine was measured by an automated version of the Jaffe method. ${ }^{6}$ The results were expressed as "total" MDA (hydrolysed metabolites plus unchanged parent MDA) in $\mathrm{nmol} / \mathrm{mmol}$ creatinine.

\section{Results}

Nine hundred and sixty samples were received; 230 workers provided both postshift and preshift (next day) urine samples and a further 396 gave only a postshift sample. Some workers provided only preshift samples. If it was not clear whether the preshift sample was taken on the day of exposure or on the next day the sample was analysed but excluded from the data set.

Most of the urine samples (about 95\%) had MDA values below $100 \mathrm{nmol} \mathrm{MDA} / \mathrm{mmol}$ creatinine. Very high concentrations $(>1300$ $\mathrm{nmol} / \mathrm{mmol}$ ) were recorded in three samples. The maximum urinary MDA concentration, $6871 \mathrm{nmol} / \mathrm{mmol}$, was found in a postshift urine sample. Examination of the data showed that $91 \%$ of postshift and $88 \%$ preshift (next day) urine samples contained less than $50 \mathrm{nmol} / \mathrm{mmol}$ (table). The shape of the frequency distribution curve was skewed and was similar for both preshift and postshift samples. Over $42 \%$ of the samples had no detectable MDA.

INDUSTRY PICTURE

In only three factories (out of 45 ) was the group average greater than $50 \mathrm{nmol} / \mathrm{mmol}$, although 15 factories had at least one worker whose urinary MDA concentration exceeded $50 \mathrm{nmol} / \mathrm{mmol}$. A similar picture was noted if the preshift (next day) urine data (38 factories) were examined. The workers in factories that had high concentrations in postshift samples tended also to have high concentrations in preshift samples.

Figure 1 shows the group average of urinary MDA plotted against the type of use. The 11 workers in the five factories that used MDA for casting and making moulds had no MDA in their urine samples. All other groups showed a range of urinary MDA values. The
Figure 1 Group average and maximum urinary $M D A$ (postshifi) plotted against type of use.

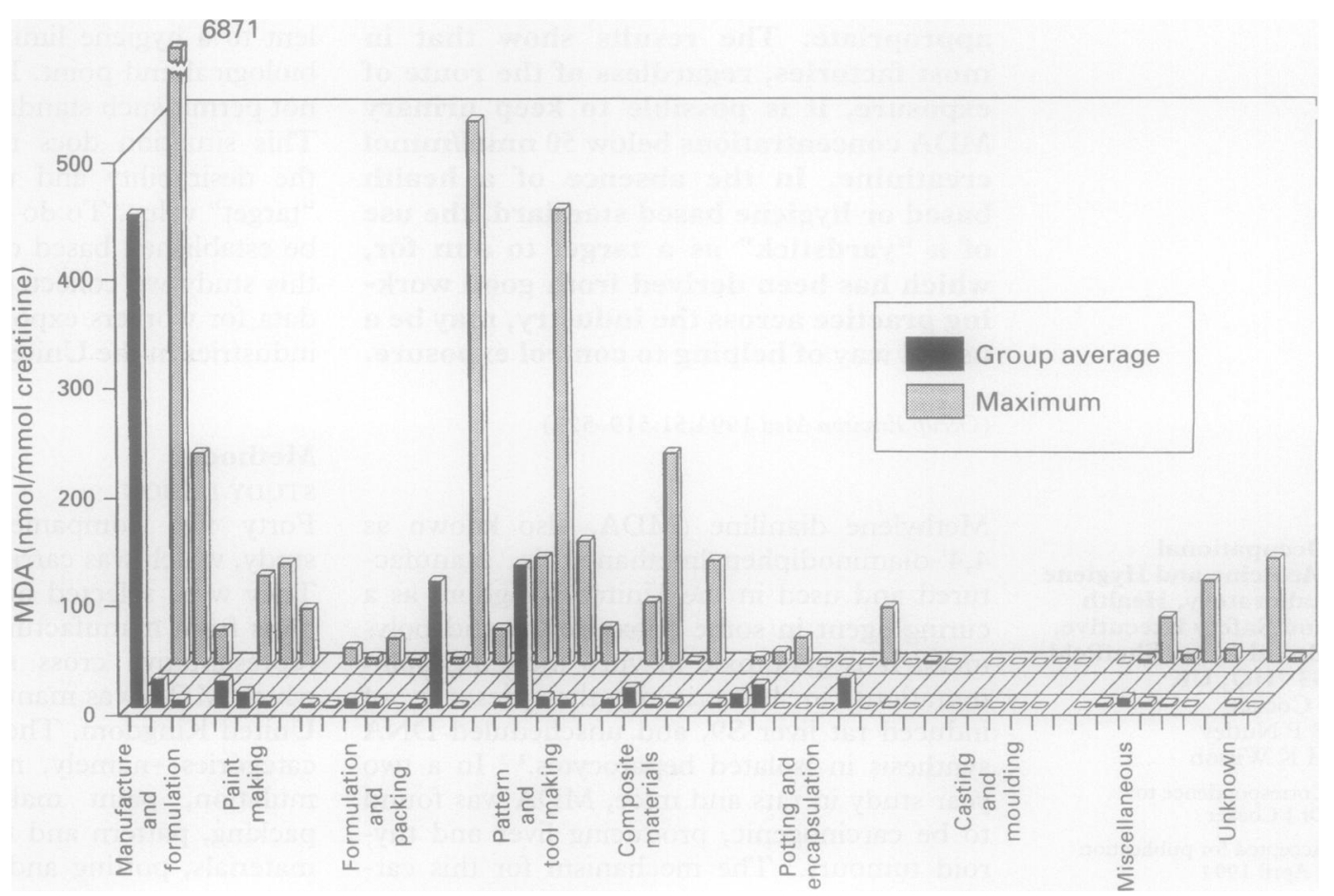


Figure 2 Urinary $M D A$ (postshift) in a worker spraying polyurethane foam. PPE = personal protective equipment.

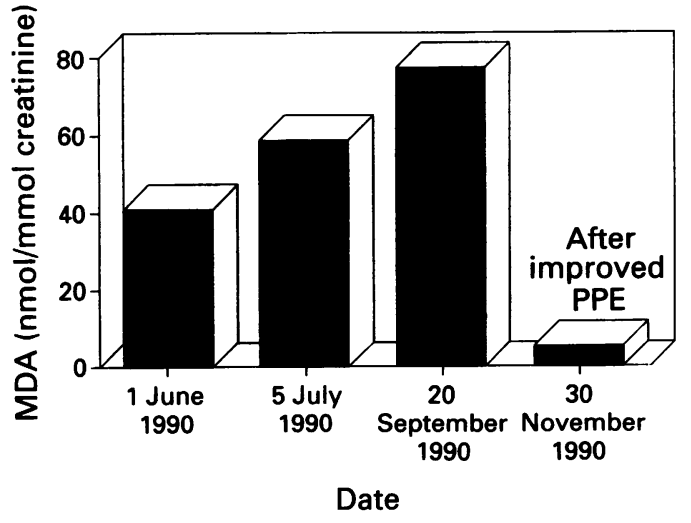

range was particularly wide among the manufacturers and formulators, for whom one factory had a group average of 450 and a maximum of $6871 \mathrm{nmol} / \mathrm{mmol}$ creatinine and another factory had a group average of 9 and a maximum of $30 \mathrm{nmol} / \mathrm{mmol}$ creatinine.

There was no correlation between the average amount of MDA processed per factory and average urinary output of MDA.

\section{THE INDIVIDUAL PICTURE}

In some cases, several urine samples from one worker were made available over some months. Figure 2 shows an example from a worker exposed to MDA during spraying polyurethane foam, and in whom the major route of entry to the body was probably via inhalation. After a third successive rise in urinary MDA, a reduction in the MDA concentration was noticed after improvements in personal protective equipment were implemented (the use of an air fed suit). On another occasion, a worker in a factory formulating MDA was required to empty $50 \mathrm{~kg}$ kegs of flaked MDA into a mixing vessel. The process took about 40 minutes and occurred midway through his shift. His urinary MDA concentrations rose from none detected to $1432 \mathrm{nmol} / \mathrm{mmol}$ creatinine postshift and had fallen to $290 \mathrm{nmol} / \mathrm{mmol}$ creatinine by preshift next day. Similar rapid rises in urinary MDA were seen for three other workers on the same process.

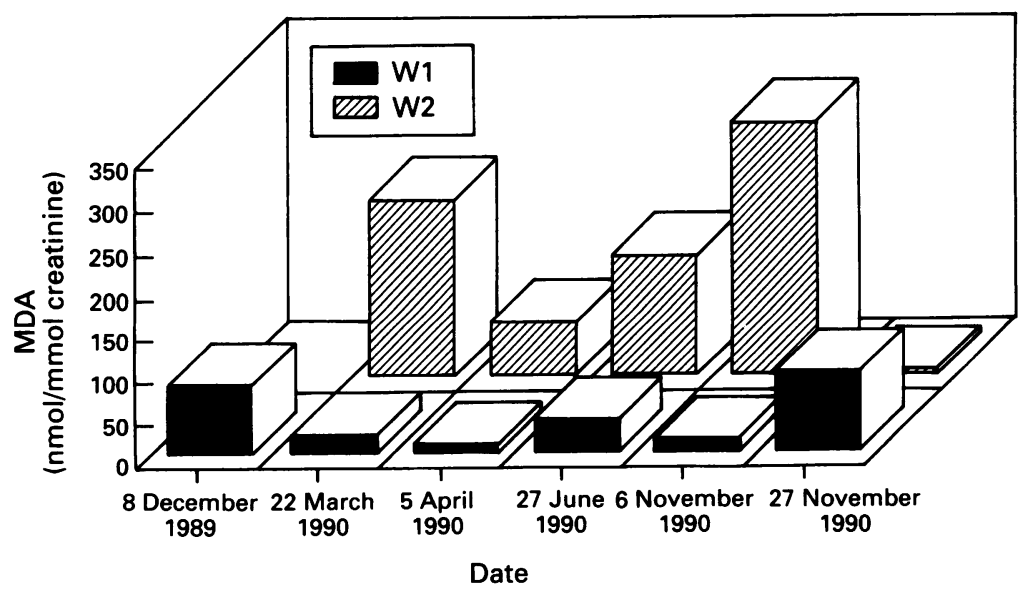

Figure 3 Urinary $M D A$ (preshift) in a supervisor and a worker formulating $M D A$. W1 = supervisor; $W 2=$ formulator.
In another factory where skin absorption was probably the main route of entry, there was little difference between the postshift and preshift (next day) group averages amongst the workers (116 and $113 \mathrm{nmol} / \mathrm{mmol}$ creatinine) and again between the maximum value seen postshift and preshift (next day) (490 and $357 \mathrm{nmol} / \mathrm{mmol}$ creatinine respectively). In figure 3 preshift (next day) urinary MDA concentrations are plotted from a supervisor and a worker formulating MDA. Preshift (next day) urine samples have been used as in the study as a whole there is a tendency for these values to be equal to or higher than postshift samples ( $\mathrm{p}<0.00002$, paired $t$ test). The supervisor (W1) had raised urinary MDA concentrations on the first and last days of the study when he covered for the mixer operator (W2).

\section{Discussion}

The principles behind the development of a biological monitoring strategy have been well rehearsed. ${ }^{78}$ Clearly, it is imperative that the analytical method employed must be sufficiently sensitive and specific to monitor the uptake of the toxic substance or its metabolites, which in turn must be stable enough to be measured. Also, the procedure must include an adequate quality assurance programme, particularly when longitudinal studies or regular monitoring are being conducted. Some indications of the route of absorption and toxicokinetics of the compound are also essential so that the most appropriate sampling time can be established.

After the strategy has been developed, and the methodology well validated, we are left with the problem of how to interpret the results. The American Conference of Governmental Industrial Hygienists (ACGIH) and Deutsche Forschungsgemeinschaft (DFG) publish annual lists of biological exposure standards for certain substances and these reflect different philosophies in the setting of standards. The ACGIH Biological Exposure Indices (BEI) is based either on the relation between exposure and uptake (a hygiene based standard) or in some cases on known health effects.9 The DFG Biological Tolerance Value (BAT) is a health based limit. ${ }^{10}$ In the case of MDA, no limits have been set. The absence of health based data however, does not preclude the use of biological monitoring for helping to control exposure, particularly where absorption of the material can occur by non-inhalation routes. In some cases, it may be appropriate to set an interim biological monitoring standard that is related to what is achievable in most industries and reflects good practice.

Biological monitoring has been used in this study to assess the uptake in exposed workers. The data give a cross sectional picture of the extent of exposure to MDA in the United Kingdom. The results indicate that where inhalation is the main route of entry into the body there is a relatively rapid absorption and elimination and peak excretion is reached at 
the end of the shift. When the material landed on the skin, the uptake was slower and the maximum excretion occurred the next morning. This study has identified the need to take into account the most likely route of exposure when devising a biological monitoring strategy. Suitable judgements need to be made as to whether postshift or preshift urine samples collected the next day would give the better indication of uptake.

In this study about $90 \%$ of workers had urinary $\mathrm{MDA}$ values less than $50 \mathrm{nmol} / \mathrm{mmol}$ creatinine. The results collected from various groups of users and manufacturers show that it is possible to control MDA exposure to keep urine concentrations below 50 $\mathrm{nmol} / \mathrm{mmol}$. This value has been proposed as a "yardstick" by the United Kingdom Health and Safety Executive."

1 Rao TK, Dorsey GF, Allen BE, Epler JL. Mutagenicity of 4,4 'methylenedianiline derivatives in the salmonella
histidine reversion assay. Arch Toxicol 1982;49:185-90.
2 Mori H, Yoshimi N, Sugi S, et al. Genotoxicity of epoxy resin hardeners in the hepatocyte primary culture/DNA repair test. Mutat Res 1988;204:683-8.

3 National Toxicology Programme. Carcinogenesis bioassay of 4,4'-methylenedianiline dihydrochloride in rats and mice. Bethesda: National Institute of Health 1983 (NIH Publ No 248).

4 Hotchkiss SAM, Hewitt P, Caldwell J. Percutaneous absorption of $4,4^{\prime}$-methylene-bis-(2-chloroaniline) and 4,4'-methylenedianiline through rat and human skin in vitro. Toxicology in vitro 1993;7:141-8.

5 Cocker J, Gristwood J, Wilson HK, Assessment of occupational exposure to 4,4'-diaminodiphenylmethane by gas chromatography/mass spectrometry analysis in urine. $\operatorname{Brf}$ Ind Med 1986;43:620-5.

6 Jaffe $M$. Measurement of creatinine using picric acid. Zeitschrift fur Physiologische Chemie 1886;10:391-400.

7 Campbell L, Marsh, DM, Wilson HK, Towards a biological monitoring strategy for toluene. Ann Occup Hyg cal monitoring

8 Health and Safety Executive. Biological monitoring for chemical exposures in the workplace. United Kingdom: HSE, 1992 (Guidance Note EH 56).

9 American Conference of Governmental Industrial Hygiene, 1992-1993. Threshhold limit values for chemical substances and physical agents and biological exposure indices. Cincinnati: ACGIH, 1992.

10 Deutsche Forschungsgemeinschaft (DFG). MAK-and $B A T$-values 1992. Weinheim: DFG 1992. (Report No 28).

11 Fairhurst S, South D, Williams C, Cocker J, Brown R. 4,4'-Methylenedianiline-criteria document for an occupa-
tional exposure limit. London: Health and Safety Executive, HMSO, 1993.

\section{Correspondence and editorials}

Occupational and Environmental Medicine welcomes correspondence relating to any of the material appearing in the journal. Results from preliminary or small scale studies may also be published in the correspondence column if this seems appropriate. Letters should be not more than 500 words in length and contain a minimum of references. Tables and figures should be kept to an absolute minimum. Letters are accepted on the understanding that they may be subject to editorial revision and shortening.

The journal also publishes editorials which are normally specially commissioned. The Editor welcomes suggestions regarding suitable topics; those wishing to submit an editorial, however, should do so only after discussion with the Editor. 